\title{
Enhancement of Solubility with Formulation \& in-vitro Evaluation of Oral Nateglinide Compacts by Liquisolid Technique
}

\author{
Mokale Vinod", Naik Jitendra, Patil Komal, Chaudhari Rahul, Khairnar Gokul \\ Department of Pharmaceutical Technology, University Institute of Chemical Technology, North Maharashtra University, \\ Jalgaon, 425 001, Maharashtra \\ *Corresponding Author: mokalevinod@gmail.com
}

Copyright @ 2013 Horizon Research Publishing All rights reserved.

\begin{abstract}
A Liquisolid system is the one of the novel technique to enhance the dissolution rate of poorly water soluble drug such as Nateglinide. In this technique liquisolid system refers to formulation of formed by water insoluble drug mix with non-volatile solvent which is further converted into free flowing, non adherent powder form and which is directly compressed into tablets. In that the propylene glycol is used as non-volatile solvent in which drug having high solubility, microcrystalline cellulose and aerosil (silica) acts as carrier and coating material in the ratio of 10:1 and 20:1 respectively. Sodium starch glycolate acts as superdisintegrants and magnesium stearate as glidant in liquisolid system. The prepared liquisolid system were evaluated to their flowing properties such as bulk density, tap density, Hausner's ratio, Carr's index, and angle of repose. Fourier Transform Infrared spectroscopy (FTIR) and X Ray Diffraction (XRD) study show no interaction between the drug and excipients. Further tablets were evaluated hardness, diameter, thickness, weight variation, friability, disintegration test, uniformity of contents and in-vitro release study show liquisolid compact exhibited higher percentage of drug release than conventional and marketed tablets because of due to increase in wetting properties and surface availability for dissolution
\end{abstract}

Keywords Nateglinide-Liquisolid Compacts, Direct Compression, In-vitro Dissolution Study

\section{Introduction}

During the last four decades the pharmaceutical industry invested the time and money in study of tablet compaction. The reason behind it the oral dosage forms are self administered by patient, they more profitable to manufacture than parenteral dosage forms. Also their low cost of manufacture, package, shipment, increased stability and tamper resistance. There are many types of tablet formulations that provide for release of drug to be delayed or control the rate of drugs availability. And some tablets are the fast disintegrating or fast dissolving tablets are present to give the quick effect of drug [1,2].

The poor dissolution rates of water insoluble drugs are still a substantial problem confronting the pharmaceutical industry. Various solid dosage formulation techniques, to enhance the dissolution of poorly soluble substances, have been introduced with different degrees of success. Drug dissolution is the single most important factor in the absorption of it, especially from the most widely used conventional solid dosage forms, tablets and capsules [3-5].

Diabetes is the metabolic disorder characterized by hyperglycemia, glycosuria, hyperlipaemia, negative nitrogen balance and ketonemia. Type II diabetes (also known as non-insulin dependent diabetes mellitus (NIDDM) or adult-onset diabetes) is one of the most serious medical conditions affecting our nation today. The number of people who have it has been rising widely. For this the fast delivery of drug is required to the diabetic patient [6].

Nateglinide (NTG) is an amino-acid derivative that lowers blood glucose levels by stimulating insulin secretion from the pancreas. This action is dependent upon functioning beta-cells in the pancreatic islets. Nateglinide interacts with the ATP-sensitive potassium (K+ATP) channel on pancreatic beta-cells. The subsequent depolarization of the beta cell opens the calcium channel, producing calcium influx and insulin secretion. The extent of insulin release is glucose dependent and diminishes at low glucose levels. The tablets have to be taken 10-20 minutes before meal [7].

The main objective of this work is to develop and explore a new formulation to enhance the bioavailability of a highly permeable and a poorly soluble antidiabetic drug Nateglinide by following liquisolid compacts. And to compare the in vitro drug release profile of formulated liquisolid tablets with marketed and conventional tablet.

\subsection{Mechanism of Solubility Enhancement}


The actual mechanism behind enhancement of solubility of drug in liquisolid compacts is the increased in surface area of drug available for release, an increase in aqueous solubility of drug, and improved wettability of drug particles present [8, 9].Due to significant increased in wetting property and surface area of drug available for dissolution [10]. The release is much greater than that of drug particles within directly compressed tablets. The drug dissolved in the liquid vehicle is incorporated into a carrier material which has porous surface. The liquid initially absorbed in the interior of the particles and it is captured by its internal structure, and after saturation of this process, adsorption of liquid onto the internal and external surfaces of porous carrier particles occur [11].

Liquid vehicle (Non-volatile solvent) present in liquisolid system can either acts as the surface active agent or has a low surface tension thus improves wetting of drug particles by decreasing interfacial tension between dissolution medium and tablet surface $[12,13]$.

\section{Materials and Methods}

\subsection{Materials}

Nateglinide was obtained from Wokhardt Research Centre, Aurangabad (M.S.) India as a gift sample. Propylene glycol, tween-80, and glycerol were purchased by Merck Specialities Pvt. Ltd., Mumbai, India. Microcrystalline cellulose and silica were purchased from Sigma Aldrich, USA, sodium starch glycolate obtained from SDFCL, Mumbai, India. Magnesium stearate was obtained from Himedia Lab. Pvt ltd, Mumbai, India. All the other chemicals and reagents were of analytical grade.

\subsection{Methods}

\subsubsection{Determination of Solubility of Nateglinide}

The solubility determination of Nateglinide was carried out in distilled water, $0.1 \mathrm{~N} \mathrm{HCl}$, propylene glycol, glycerol, and tween-80. The excess drug was added gradually to $10 \mathrm{ml}$ of each solvent contained in $100 \mathrm{ml}$ beaker. The beaker was place on magnetic stirrer for $24 \mathrm{hr}$ until solubility equilibrium was reached. The solutions were filtered through Whatmann filter paper. Aliquots of the filtrate were suitably diluted and the dilutions were analyzed spectrophotometrically at $212 \mathrm{~nm}$.

Application of mathematical model for preparation of liquisolid tablets:

\subsubsection{Determination of liquid load factor (Lf)}

It is defined as the ratio of liquid medication (w) to weight of coating material (q). It is determined by dissolving or dispersing the drug in non volatile solvent and to this carrier-coating material admixture is added and blended. The amount of carrier-coating admixture is used to convert free flow powder and is determined by using the following formula.

$\mathrm{Lf}=\mathrm{W} / \mathrm{Q}$

Where, $\mathrm{W}=$ Weight of liquid medication

$\mathrm{Q}=$ weight of carrier material

The $\Phi$ value is for calculating excipients quantities. Equation is

$$
\mathrm{Lf}=\Phi+\Phi(1 / \mathrm{R})
$$

Where, $\Phi$ and $\Phi$ are values of carrier and coating material [14].

It is used to calculate amount of carrier and coating material in each formulation.

The excipients ratio $\mathrm{R}$ of powders is defined as the ratio of carrier and coating material present in the formulation. $\mathrm{R}$ is suitably selected for successful formulation.

$$
\mathrm{R}=\mathrm{Q} / \mathrm{q}
$$

Where, $\mathrm{Q}=$ weight of carrier

$\mathrm{Q}=$ coating material $[15,16]$

\subsubsection{Determination of holding capacity of the excipients}

The capacity of each excipient to hold liquid and behave like dry powder (holding capacity) was determined using the following simple technique: Different weights of Propylene glycol were transferred to a mortar. The constant weight of powder excipient was added gradually and the mixture was triturated after each addition to help distributing the liquid throughout the powder particles. The addition of powder and the trituration was continued until mortar contents start to look like dry powder [17].

\subsubsection{Formulation of Nateglinide Tablets by liquisolid technique}

\subsubsection{Preparation liquisolid compacts}

Weigh accurately $60 \mathrm{mg}$ Nateglinide in each batch and place in the mortar and add the propylene glycol as non-volatile solvent to form dispersion mix well. Add the small amount of the binary mixture of carrier and coating material (microcrystalline cellulose and silica) in it and mix. Depending upon the type of carrier in formulation, different liquid loading factors were employed in liquisolid preparations. Finally, $5 \%$ (w/w) of sodium starch glycolate as disintegrant and 1\% magnesium stearate were mixed with mixture for 5 minutes. Final mixture was compressed on 13 mm punch and die, using the manual hydraulic press at constant pressure. The batch design is reported in table 1 . $[17,18]$.

\subsubsection{Preparation of conventional tablets}

Weigh accurately drug Nateglinide place in the mortar and the specific amount of the binary mixture of carrier and coating material (microcrystalline cellulose and silica) in it and mix. Finally, $5 \%(w / w)$ of sodium starch glycolate as disintegrant and 1\% magnesium stearate were mixed with mixture for 5 minutes. Final mixture was compressed on 13 mm punch and die, using the manual hydraulic press at 
constant pressure $[14,15]$.

Table1. Formulation design of NTG Liquisolid compacts

\begin{tabular}{|c|c|c|c|c|c|}
\hline Batch & $\begin{array}{c}\text { Non } \\
\text { volatile } \\
\text { solvent }\end{array}$ & $\begin{array}{c}\text { Carrier } \\
\text { coating } \\
\text { material }\end{array}$ & $\begin{array}{c}\mathrm{R} \\
\text { Value }\end{array}$ & $\begin{array}{c}\text { Lf } \\
\text { Value }\end{array}$ & $\begin{array}{c}\text { Tablet } \\
\text { wt }\end{array}$ \\
\hline A & 120 & 400 & 10 & 0.3 & 580 \\
\hline B & 120 & 600 & 20 & 0.3 & 780 \\
\hline C & 90 & 320 & 10 & 0.4 & 470 \\
\hline D & 90 & 450 & 20 & 0.3 & 600 \\
\hline E & 60 & 250 & 10 & 0.4 & 370 \\
\hline F & 60 & 200 & 20 & 0.6 & 320 \\
\hline G & ---- & 400 & --- & --- & 460 \\
\hline
\end{tabular}

*5\% SSG + 1\% Mg-stearate are added

\section{Evaluations}

\subsection{Flow Properties}

Flow properties of liquisolid formulation were studied by angle of repose, Carr's index, and Hausner's ratio. Each analysis was carried out in triplicate. Bulk density measurements were carried by placing a fixed weight of powder in a graduated cylinder, and the volume occupied was measured and the initial bulk density was calculated. The cylinder was then tapped at a constant velocity until a constant volume was obtained. The tapped density was then calculated. The angle of repose was calculated by the fixed-height cone method. All studies were done in triplicate. Then after the Carr's index, and Hausner's ratio was calculated from bulk and tapped density [17].

\subsection{FTIR Spectra Analysis}

In the preparation of liquisolid Tablets, NTG and excipients may interact as they are in close contact with each other, which could lead to the instability of drug to overcome this problem, FTIR Spectroscopy was employed to ascertain the compatibility between NTG and excipients.

\subsection{Evaluation of Liquisolid Tablets}

\subsubsection{Hardness:}

The hardness of liquisolid tablets was determined using Monsanto hardness tester. The mean hardness of each was determined.

\subsubsection{Diameter and Thickness:}

The diameter and thickness of tablets were calculated by Vernier calliper.

\subsubsection{Weight variation}

Weight variation was measured by weighing 20 tablets and average weight was found of the individual tablet should fall within specified limits.

\subsubsection{Friability}

The friability of the tablets was determined by laboratory friability tester known as Roche Friabilator, the percentage loss in tablet weight before and after 100 revolutions of 10 tablets were calculated and taken as percentage friability.

\subsubsection{Disintegration Test}

The disintegration test is done using USP disintegration test apparatus.

\subsubsection{Uniformity of contents}

5 tablets were weighed individually and crushed in a mortar. Quantity of powder equivalent to $10 \mathrm{mg}$ of Nateglinide was weighed accurately and dissolved in $0.01 \mathrm{~N}$ $\mathrm{HCl}$ with $0.5 \%$ sodium lauryl sulphate. The volume was made to $100 \mathrm{ml}$ with solvent. Appropriate dilutions of the resulting solutions were done. The drug contents of the resulting solutions were calculated from recorded UV absorbances at 212nm. [4, 19].

\subsubsection{FTIR spectra analysis}

In the preparation of liquisolid Tablets, NTG and excipients may interact as they are in close contact with each other, which could lead to the instability of drug. FTIR Spectroscopy was employed to ascertain the compatibility between NTG and excipients.

\subsubsection{X-Ray diffraction study}

For further characterization of the crystalline state, the X-ray diffraction (XRD) patterns were determined for Nateglinide powder and Liquisolid formulation were are analysed by powder X-Ray Diffractometer (D8 ADVANCE, Bruker, Germany) with $\mathrm{Cu} \mathrm{K \alpha}$ radiation (1.540 $\AA$ ), in the range of $2 \theta=20-60 \mathrm{o}$ at slow angle scan of $0.020 /$ step. The results were then obtained as peak height (intensity) versus $2 \theta$.

\subsubsection{In-Vitro Release Study}

The in vitro dissolution studies were carried out by using USP Type II (Paddle type) (Electrolab TDT 06) dissolution test apparatus. All bathes of liquisolid tablets were evaluated by using $1000 \mathrm{ml}$ of $0.01 \mathrm{~N} \mathrm{HCl}$ with $0.5 \%$ sodium lauryl sulphate. Following parameters were used during release study. Speed of paddle $50 \mathrm{rpm}$, temperature $37 \pm 2^{\circ} \mathrm{C}$ Sampling time 5,10,15,20,30,45,60 minutes, filtered using (Millipore Millex-HN), and analyzed spectrophotometrically at $212 \mathrm{~nm}$. The spectrophotometric readings were converted into cumulative percent of drug release using the standard calibration curve of Nateglinide [20].

\section{Result}




\subsection{Determination of Solubility of Drug}

The Fig.1 gives experimentally determined solubility of used drug substances in distilled water, $0.1 \mathrm{~N} \mathrm{HCl}$, propylene glycol, Glycerol and Tween 80. The drug shows low solubility in distilled water, $0.1 \mathrm{~N} \mathrm{HCl}$, glycerol and shows significant solubility in Tween 80 and propylene glycol. Hence propylene glycol was used in this study

\subsection{Flow Properties}

The flow properties of liquisolid powders were analysed before compression to compact. By using bulk density, tap density, hausners ratio, and Carr's index. The hausners ratio below 1.25 shows good flowability for direct compressible tablet. The Carr's index is between 12 to 21 shows good to fair flowability. The angle of repose between 31 to 40 shows good to fair flowability of powder. The Hausners ratio of batch $\mathrm{G}$ shows more than normal. The Carr's index of batch $D$ and $G$ shows more values. The angle of repose of the all batches shows acceptable results reported in table 2 .

\subsection{Evaluation of Tablets}

The diameter and thickness of the tablets were varied with all batches because of the all bathes having variable in their weight. The uniformity of contents of tablets is between 89.44 to $100.97 \%$ which is acceptable for further study. Hardness of tablet was determined by Monsanto hardness tester hence average hardness was found to be between 3.7 to $4.1 \mathrm{~kg} / \mathrm{cm}^{2}$, stated in table 3

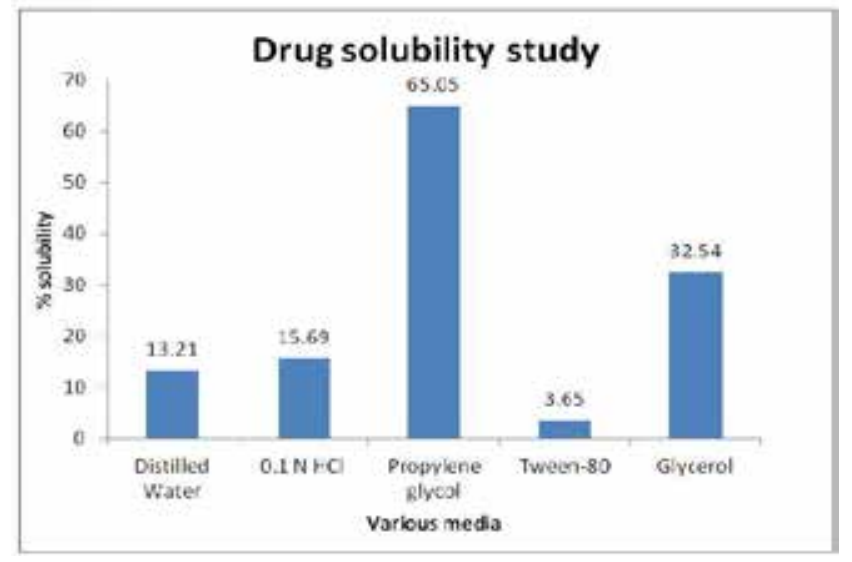

Figure 1. Drug Solubility profile of NTG

Table 2. Flow properties of Liquisolid compressible powder

\begin{tabular}{|c|c|c|c|c|c|}
\hline Batch & $\begin{array}{c}\text { Bulk Density } \\
\mathbf{( g m / m l )}\end{array}$ & $\begin{array}{c}\text { Tap Density } \\
\mathbf{( g m / m l )}\end{array}$ & Hausner's Ratio & Carr's Index & Angle of Repose \\
\hline A & $0.38 \pm 0.005$ & $0.45 \pm 0.14$ & $1.18 \pm 0.03$ & $16.5 \pm 3.8$ & $29.8 \pm 2.1$ \\
\hline B & $0.32 \pm 0.002$ & $0.31 \pm 0.11$ & $1.05 \pm 0.08$ & $15.5 \pm 1.4$ & $30.7 \pm 4.8$ \\
\hline C & $0.44 \pm 0.003$ & $0.53 \pm 0.17$ & $1.08 \pm 0.17$ & $16.8 \pm 0.5$ & $33.7 \pm 0.6$ \\
\hline D & $0.46 \pm 0.004$ & $0.61 \pm 0.19$ & $1.14 \pm 0.28$ & $25.2 \pm 0.8$ & $34.8 \pm 2.2$ \\
\hline E & $0.36 \pm 0.002$ & $0.39 \pm 0.13$ & $1.24 \pm 0.01$ & $20.1 \pm 0.6$ & $36.7 \pm 2.4$ \\
\hline F & $0.37 \pm 0.002$ & $0.43 \pm 0.13$ & $1.21 \pm 0.10$ & $12.3 \pm 0.1$ & $38.4 \pm 0.7$ \\
\hline G & $0.35 \pm 0.002$ & $0.46 \pm 0.14$ & $1.30 \pm 0.01$ & $23.3 \pm 0.5$ & $36.6 \pm 2.3$ \\
\hline
\end{tabular}

Table 3. Post-compression evaluation of liquisolid compacts

\begin{tabular}{|c|c|c|c|c|c|c|c|}
\hline Batch & $\begin{array}{c}\text { Diameter } \\
\mathbf{( m m})\end{array}$ & $\begin{array}{c}\text { Thickness } \\
\mathbf{( m m})\end{array}$ & $\begin{array}{c}\text { Uniformity of } \\
\text { contents (\%) }\end{array}$ & $\begin{array}{c}\text { Hardness } \\
\left.\mathbf{( K g} / \mathbf{c m}^{\mathbf{2}}\right)\end{array}$ & $\begin{array}{c}\text { Weight } \\
\text { Variation (mg) }\end{array}$ & $\begin{array}{c}\text { DT } \\
\mathbf{( s e c} .)\end{array}$ & Friability (\%) \\
\hline $\mathbf{A}$ & $13.14 \pm 0.01$ & $2.97 \pm 0.18$ & $95.77 \pm 0.21$ & $3.7 \pm 0.08$ & $517.85 \pm 0.02$ & $151 \pm 0.69$ & $0.77 \pm 0.077$ \\
\hline $\mathbf{B}$ & $13.17 \pm 0.04$ & $4.44 \pm 0.02$ & $100.97 \pm 0.13$ & $3.6 \pm 0.08$ & $767.4 \pm 0.04$ & $154 \pm 0.01$ & $0.16 \pm 0.04$ \\
\hline $\mathbf{C}$ & $13.51 \pm 0.8$ & $2.77 \pm 0.07$ & $94.95 \pm 0.45$ & $4.1 \pm 0.09$ & $435.75 \pm 0.05$ & $186 \pm 0.02$ & $0.2 \pm 0.08$ \\
\hline $\mathbf{D}$ & $13.13 \pm 0.01$ & $3.94 \pm 0.1$ & $97.07 \pm 0.37$ & $3.8 \pm 0.04$ & $614.9 \pm 0.01$ & $152 \pm 0.05$ & $0.13 \pm 0.04$ \\
\hline E & $13.16 \pm 0.03$ & $2.16 \pm 0.1$ & $89.44 \pm 0.67$ & $4.1 \pm 0.14$ & $336.75 \pm 0.03$ & $256 \pm 0.04$ & $0.1 \pm 1.3$ \\
\hline F & $13.14 \pm 0.02$ & $1.89 \pm 0.05$ & $98.05 \pm 0.12$ & $4.1 \pm 0.16$ & $333.6 \pm 0.6$ & $204 \pm 0.01$ & $0.16 \pm 0.04$ \\
\hline G & $13.15 \pm 0.02$ & $2.82 \pm 0.07$ & $99.35 \pm 0.31$ & $4.1 \pm 0.24$ & $453.85 \pm 0.2$ & $381 \pm 0.05$ & $0.43 \pm 0.04$ \\
\hline
\end{tabular}


The disintegration time test revealed that the all formulations disintegrated in less than 250 seconds, only the conventional tablet shows more time to disintegrate. All the Nateglinide liquisolid tablets had acceptable friability which had no exceed than the $1 \%$, no tablet was crack or broken in all batches. Since all the prepared batches shows acceptable durability and withstand abrasion in handling, packaging and shipment.

\subsection{FTIR Interference Study}

The FTIR spectrum of pure Nateglinide showed an absorption band at $2924 \mathrm{~cm}-1$ (aliphatic C-H stretching; asymmetric), 2859 cm-1 (aliphatic CH stretching; symmetric, $1713 \mathrm{~cm}-1$ (C = O stretching for Ketone), $3064 \mathrm{~cm}-1$ (aromatic C-H Stretching), $3086 \mathrm{~cm}-1$ (aromatic C=H Stretching). The FTIR spectrum of physical mixture and pure Nateglinide show all the peaks for drug and other excipients, hence no interaction was observed between them. The results were shown in Fig.2 and Fig.3.

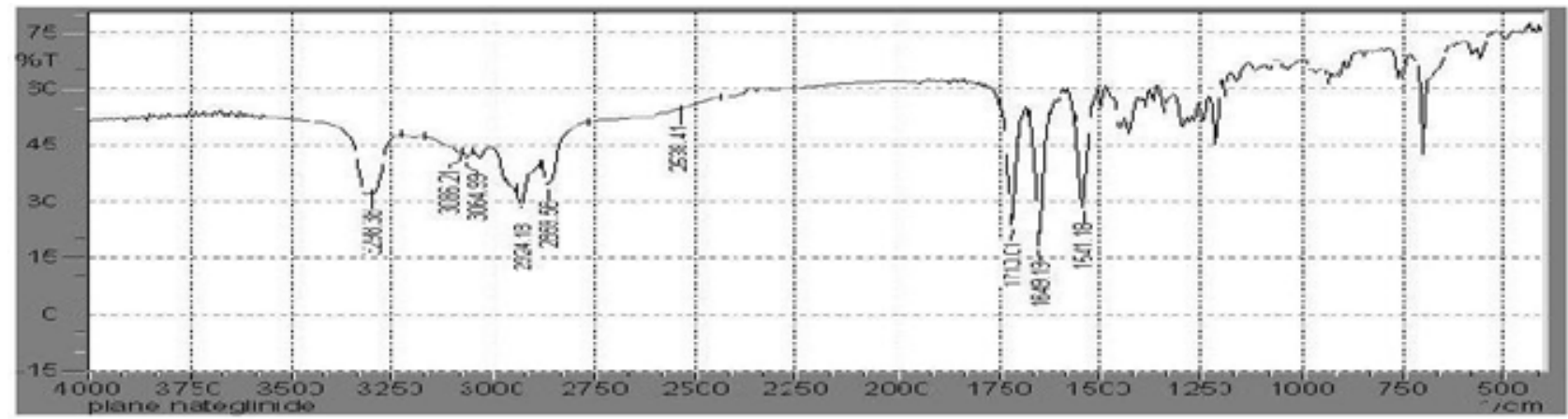

Figure2. IR Spectra of plane Nateglinide

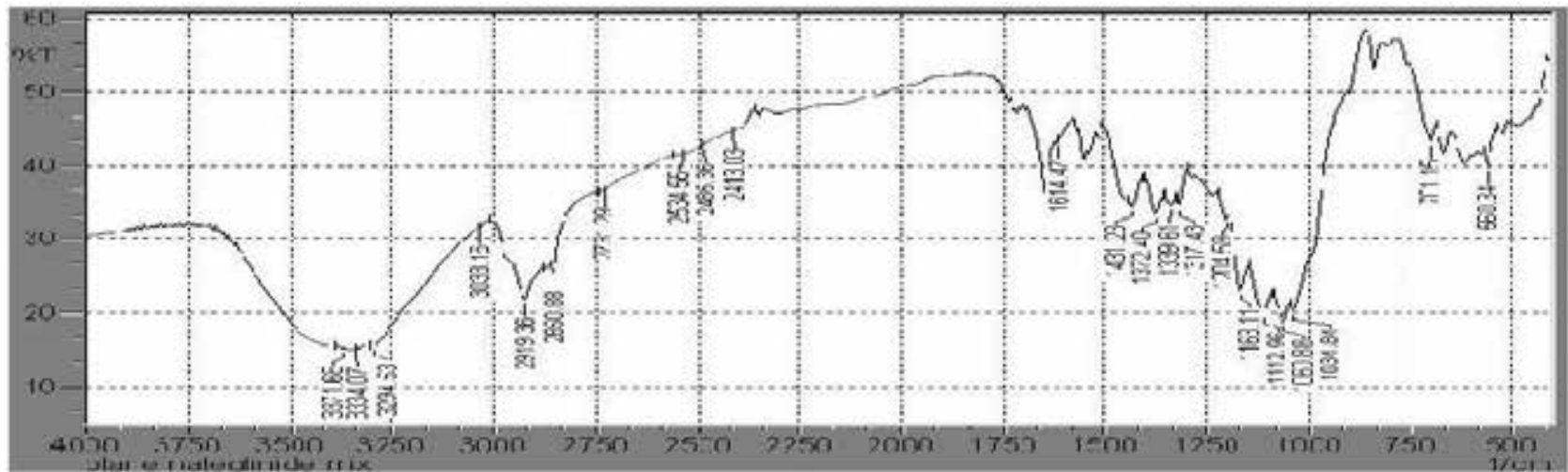

Figure 3. IR Spectra of NTG Physical Mixture

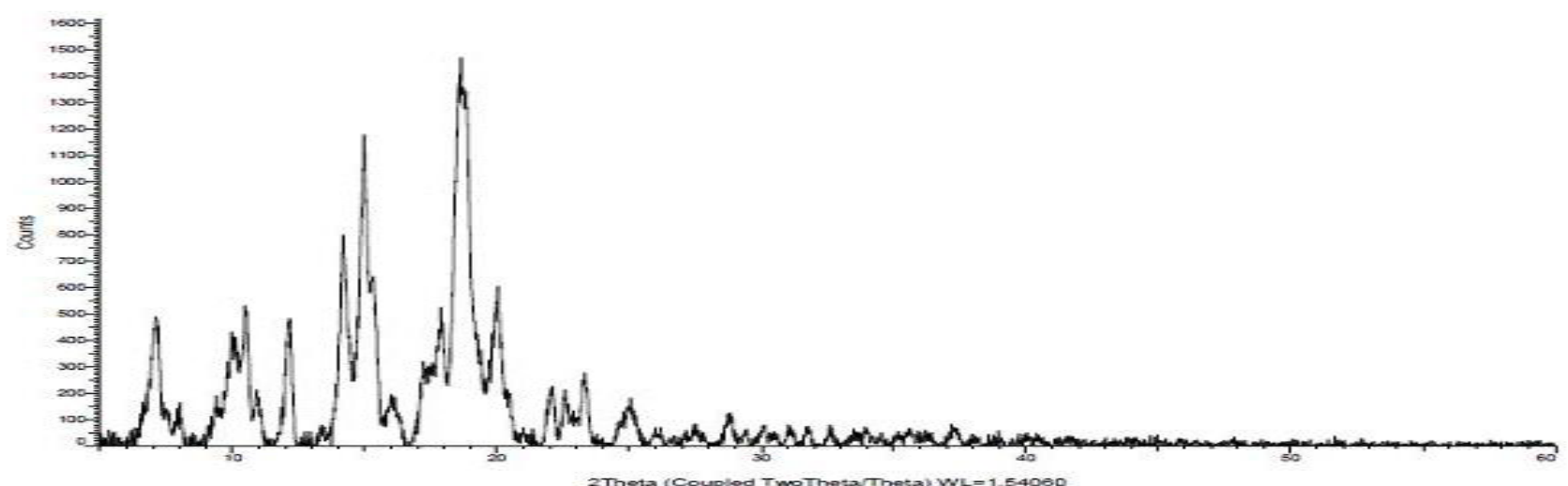

Figure 4. X-Ray Diffraction Pattern of Pure Nateglinide drug 


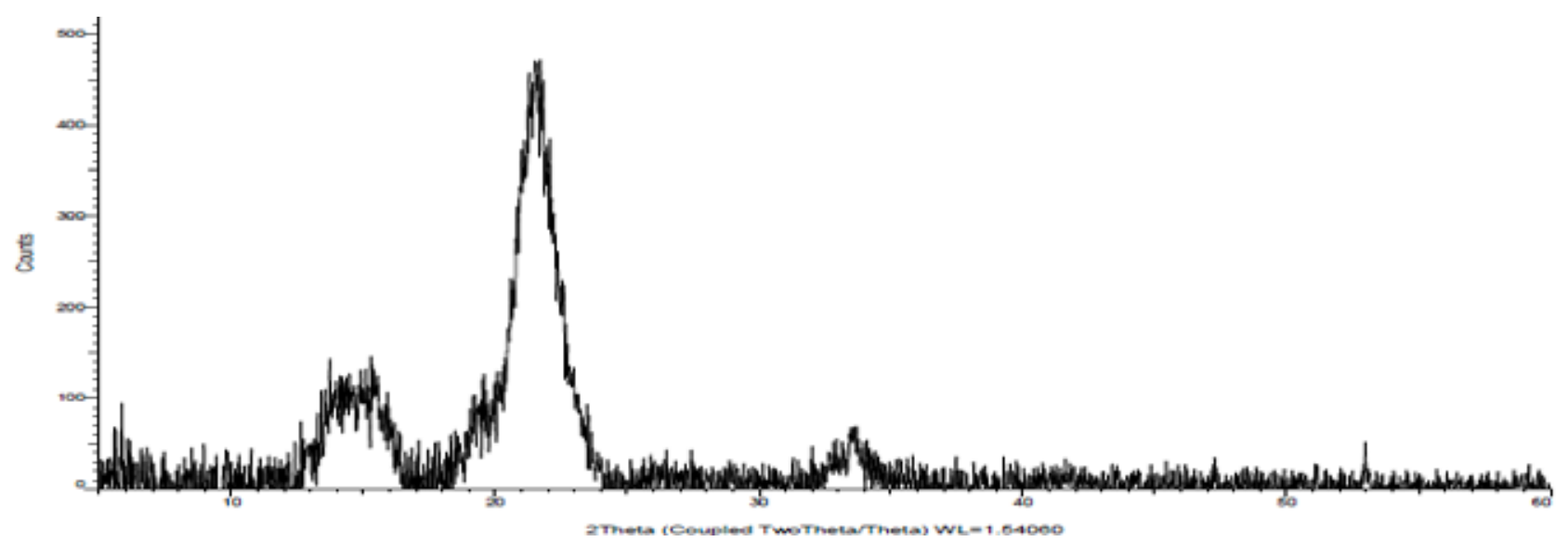

Figure 5. X-Ray Diffraction Pattern of Phaysical mixture of Nateglinide and Excipients

\subsection{X-Ray Diffraction study}

X-ray diffraction patterns in Fig.4 revealed that pure Nateglinide was clearly in crystalline state as it showed sharp distinct peaks notably at $2 \theta$ diffraction angles of $5 \theta$, $10.5 \theta, 12 \theta, 15 \theta$ and $19 \theta$. In the Fig.5 clearly show that the disappearance of $2 \theta$ angles in the liquisolid compact formulation is evident that crystalline pure drug is converted into amorphous state due to its molecular solubilization of the drug in the non-volatile solvent, which proves the enhancement of solubility by this technique.

\subsection{In-Vitro Release Study}

In the dissolution study of Nateglinide liquisolid compact the order of improving the dissolution rate is $\mathrm{B}>\mathrm{A}>\mathrm{C}>\mathrm{D}>$ $\mathrm{F}>\mathrm{E}$ show in Fig. 6. The batch B having 1:2 ratios showed more increase in solubility and dissolution having $96.27 \%$ cumulative drug release. Fig.7.shows the conventional tablets $88.92 \%$ and marketed tablets had Compressible powder $91.94 \%$ release. Hence the batch (B) was considered as optimized batch since it showed $78.99 \%$ in first 5 minute release which is statistically significant difference in both solubility and dissolution characteristic as compared to other ratio. It was also observed that the liquisolid compacts show the better drug release than conventional and marketed tablets. Results were shown in Fig. 6 and 7.

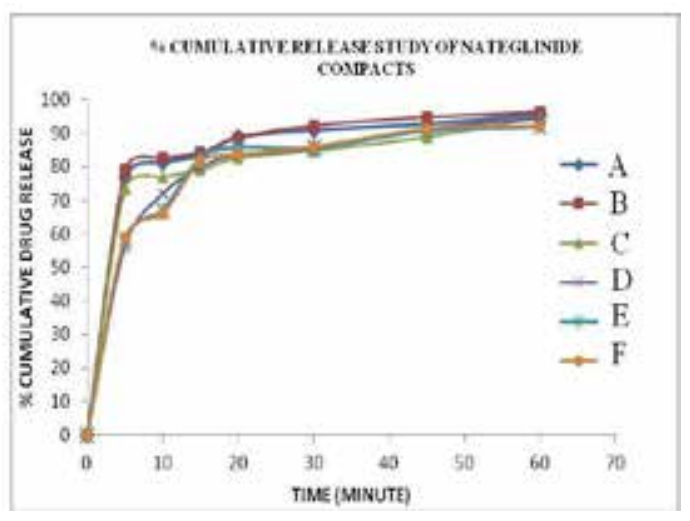

Figure 6. Dissolution profile of liquisolid batches

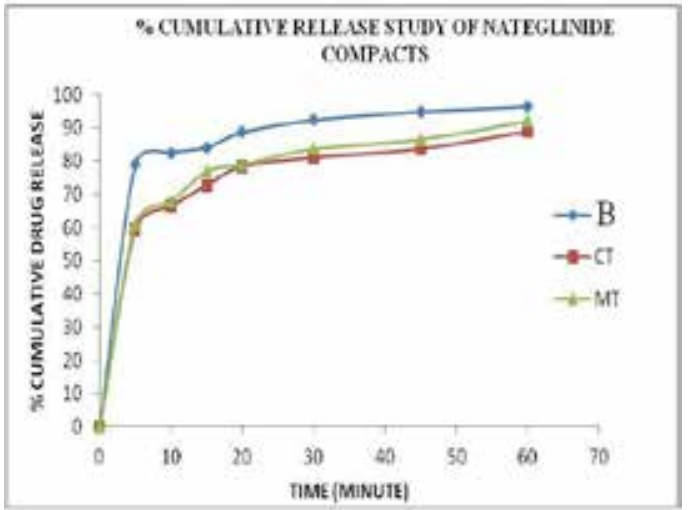

Figure 7. Comparative Dissolution profile of Batch B with conventional (CT) and Marketed (MT) Tablets

\subsection{Stability Study}

Results of stability studies showed that there was no significant change in hardness, friability and in vitro disintegration time of Nateglinide liquisolid compacts. Thus the results showed that the formulations have good stability.

\section{Discussion}

Liquisolid compacts is the technique in which the drug is mixed with non-volatile solvent and which is again mixed with carrier and coating material which have specified ratio and finally added superdisintegrants and Glidant. Nateglinide compacts where prepared by liquisolid system. In literature the liquisolid compacts of Nateglinide is not found hence the study is selected and other techniques for solubility enhancement are given on this drug such as nanoparticles, solid dispersions. In this technique actual mechanism of increasing in solubility is the wetting of drug particle and increase in surface area of the drug due to that the solubility of drug get increased. The study shows that the solubility of Nateglinide is very less in water and hence the various non-volatile solvents having more solubility than the water hence among tween-80, glycerol, propylene glycol 
shows more solubility of Nateglinide. Hence propylene glycol is selected for the preparation of liquisolid compacts. The microcrystalline cellulose and aerosil was selected as carrier and coating material. Then sodium starch glycolate and magnesium stearate was added as the super disintegrant and Glidant in the formulation. The FT-IR and X-Ray diffraction studies show no interaction between drug and excipients. The finally compressed into the tablets using manual tabletting machine by alternatively cheking hardness of the tablets. The evaluation of the liquisolid compacts was done by two parts such as pre-compression study and post-compression study. In pre-compression study the all parameters like flow properties bulk density, tap density, angle of repose, Hausner's ratio and Carr's index was performed and shows the significant results. In post compression evaluation the diameter, thickness, hardness, weight variation, disintegration time, friability was done. The in-vitro evaluation of the Nateglinide liquisolid compacts compared with all bathes the batch having more non-volatile solvent shows fast release of the drug from the compacts such as batch B shows fast release of drug than other bathes. The batch B which is compared with conventional (CT) and marketed tablets (MT) the liquisolid compacts shows significant release than that conventional and marketed tablet. Hence the liquisolid compact is the promising tool for enhancement of solubility of water insoluble drug.

\section{Acknowledgments}

The authors are grateful to Defence Research and Development Organization (DRDO), Ministry of Defence, New Delhi, Govt. of India, for providing financial support, in terms of Major Research Project [F. No. ERIP/ER/0903820/M/01/1379]. Authors also would like to thank Wockhardt Research Center, Aurangabad (M.S.) India for providing free sample of drug.

\section{Declaration of Interest}

No conflict of interest.

\section{REFERENCES}

[1] Banker GS, Rhodes CT. Modern Pharmaceutics,Fourth edition, Revised and expanded, (2002) Marcel Dekker.

[2] Jadhav D S, Mokale V J, Patil A P, Kumar P, Chaudhari R B .Novel approach for controlled drug delivery: pulsatile drug delivery systems. Inventi Rapid: NDDS (2012) 4 (15):343

[3] Brahmankar DM, Jaiswal SB. Biopharmaceutics And Pharmacokinetics-A Treatise, Vallabh Prakashan, First Edition, (2008):19-22.
[4] Lachman L, Liberman HA, Kanig JL. The Theory and Practice of Industrial Pharmacy,Varghese Publishing House, (1991):302.

[5] Chaudhari R, Mokale V, Chetan C Review on: bioavailability enhancement by solid dispersions. Inventi Rapid: NDDS (2012) 10 (15):435

[6] Tripathi KD. Essentials of Medical Pharmacology, 6th Edition, Reprint 2009, Jaypee Brothers Medical Publishers, (2008):254,269.

[7] Novartis Prescribing Information, Starlix ${ }^{\circledR}$ (Nateglinide Tablets), Reference Id: 3005356, Page No.01

[8] Yadav VB, Yadav AV. Enhancement of solubility and dissolution rate of BCS class II pharmaceuticals by non aqueous granulation technique. International Journal of Pharma Research And Development.(2010) 1(12)

[9] Khairnar GA, Sayyad FJ.Development of buccal drug delivery system based on mucoadhesive polymers, International Journal of PharmTech Research.(2010)2(1): 719-735

[10] Spireas S, Sadu S. Enhancement of prednisolone dissolution properties using liquisolid compacts. Int. J. Pharm.(1998) 166: $177-188$.

[11] Rania H, Fahmy MAK. Enhancement of famotidine dissolution rate through liquisolid tablets formulation: In vitro and in vivo evaluation, European Journal of Pharmaceutics and Biopharmaceutics (2008) 69:993-1003.

[12] Patil U, Patil S, Kumar G, Liquisolid Compacts: A Review, International Journal of Pharmaceutical Research And Development. (2012) 4 (03):151-157.

[13] Javadzadeh Y, Siahi-Shadbad M R. Barzegar J, Nokhodchi A. Enhancement of dissolution rate of piroxicam using liquisolid compacts, IL Farmaco (2005) 60:361-365.

[14] Chaudhari R, Mokale V. Liquisolid Compacts: A NovelApproach for Drug Delivery. Inventi Rapid: NDDS.(2012) 7(15):365.

[15] K. Rajesh, R. Rajalakshmi, J. Umamaheswari, C.K. Ashok Kumar, Liquisolid Technique A Novel Approach To Enhance Solubility And Bioavailability, International Journal of Biopharmaceutics. (2011) 2(1): 8-13.

[16] Spireas, United States Patents, Patent No.US 6,423,339B1.

[17] Khalid M. El-Say, Ahmed M. Samy Mohamed I. Fetouh. Formulation And Evaluation of Rofecoxib Liquisolid Tablets, Journal of Pharmacy Research. (2010) 3(10):2388-2392.

[18] Chuahan PV, Patel HK, Patel KN, Patel PA, Liquisolid Technique for Enhancement of Dissolution Rate of Ibuprofen, Int. J. Pharm. Research Scholars (2012) V-1, I-2:268-280.

[19] Indian Pharmacopoeia-2007, The Indian Pharmacopoeia Commission, Ghaziabad, 175-187.

[20] www.accessdata.fda.gov/scripts/cder/dissolution/dsp_S earchResults Dissolutions.cfm Accessed on 01 September (2012)

[21] Mokale VJ and Patel KG, Formulation, development and evaluation of Fluconazole gel in various polymer bases 
Asian J Pharm 1 (8), (2007):63-68.

[22] Mokale VJ, Borkar SN, et al, An approach to formulate bilayered gastroretentive floating drug delivery system of cefpodoxime proxetil, International Journal of ChemTech Research, 2, (2010):1229-1242.

[23] Naik J B. Mokale V J., Formulation and evaluation of
Repaglinide nanoparticles as a sustained release carriers, Novel Science International Journal of Pharmaceutical Science, (2012):259-266.

[24] Naik JB, Mokale VJ, DB More, MM Bari, RB Chavhan, BB More, Failure of Functionality of Coated Pellets into Tablets- Problems and Solutions, Research Journal of Pharmacy and Technology, (2011) 4 (1):43-46. 